\title{
Redesigning of Shopping Cart for Cost Reduction Using DFMA
}

\author{
C. D. Naiju, Pranav. V. Warrier and V. Jayakrishnan
}

School of Mechanical Engineering, VIT University, Vellore, India

\begin{abstract}
Product Design is a way of creating new designs for various products to be sold by a business to customers. It is very efficient as certain new designs and ideas can lead to products with less cost. The two methodologies of design for manufacture and assembly (DFMA) include design for manufacture (DFM) which is concentrated on reducing the number of redundant parts for the ease of manufacturing and also design for assembly (DFA) which is concentrated on reducing the assembly time of the parts included in the design of the product. It also helps to reduce the inefficiency and waste in the product design. This paper includes a case study of manufacture and assembly costs estimation of a shopping cart which is widely used in supermarkets, department stores all around the world. The main aim of this paper is to reduce the overall manufacturing cost of the shopping cart. The CAD model of the different parts of the shopping cart was generated using solid works and then analysed using the DFMA software. The outcomes were studied and the re-design is done. The final assembly cost of the re-designed product was compared to that of the existing design and the results are discussed.
\end{abstract}

\section{Introduction}

The demand for consumer products increases day by day and the technological advancements and development in the industries increases the demand of the products in market. To meet this demand, speed and the production capability must be increased. The ease in manufacturing provided by DFMA was studied by Andrew et al [1] where the end result was the detailed design of manufacturing assembly line. To improve in the product design process, design for manufacture and design for assembly were combined to form as design for manufacture and assembly (DFMA). The effectiveness of the new method was tested on a heavy duty stapler.

A study showed that a complete DFMA analysis helped give a categorical approach to the cost to be infused with each division within the firm. This enables the product designers to use all resources to the most optimized capabilities. As a result of which, more efficient product with less cost can be developed and thus improving sales [2]. According to Dewhurst et al [3], early cost estimation in product design is intended to form the basis for the design analysis for product design for efficient manufacture.

The methodology of DFMA can be used effectively to reduce the overall manufacturing costs by reducing the number of parts in the product and also by redesigning some parts to reduce the material used. [4].

Recent studies also showed that material selection process can help the product designers to find out what kind of aspects of materials are significant in their selection [5].
Design for Assembly evaluation is a systematic approach in determining how well a product is designed from assembly point of view. A study discusses a framework for automating DFA evaluation procedure, which is a key step in achieving a concurrent design environment. The modules required for this are assembly sequence generation, assembly features extraction, assembly code and other necessary operations generation, data manipulation and computation and re-design suggestion [6]. Recent studies about DFMA is related to the products likediesel engine, washing machine, refrigerators which has turned to be more effective as they are used in daily lives which makes them quite important. The abundant number of products around the world is also another reason to take consumer products under the DFMA technology [7].

\section{Shopping cart - A case study}

A shopping cart or buggy as used in some parts in United States and Canada, is a trolleywhich is supplied by a shop, especially supermarkets, department stores, for use by the customers inside the store to transport the merchandises from the shopping are to the checkout counter. Customers can also transport it to the parking lots outside the stores. Customers can take or leave the shopping cart outside the premise of the supermarket. This is very common in our day to day life and it is an improvement over the old shopping basket where customers had to carry it in their arms. This shopping basket became impractical. A large amount of merchandises could be transported using the shopping 
cart. This was possible with the help of wheels at the bottom of the cart. Carts in different designs are used all over around the world like trolleys in airports which helps passengers move heavy luggage easily from drop off area to check in as well as from the luggage carousel to the arrival area. The existing design available by all the leading department stores is given in the Fig. 1.

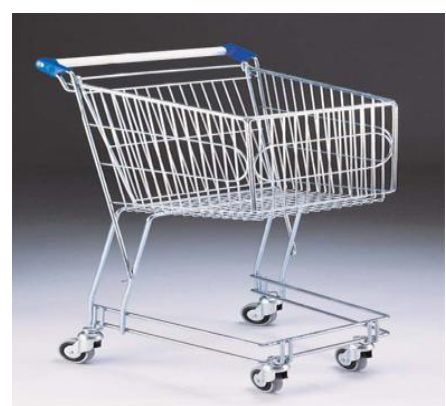

Figure 1. Existing shopping cart model.

Main parts in the shopping cart are castor wheels, frame, trim, mesh, handle and under carriage. These parts form the main parts, but there are a total of 26 parts in the existing design taken up for study. The different parts and their CAD models are given in Table 1. The processes included in the manufacturing of the shopping car include cutting (Advanced), automated bending, jig loading, spot welding, trimming, die punching, metal cleaning and finally the parts assembly.

In order to implement DFMA methodology to find the cost estimate included in the manufacturing of the shopping cart, the CAD models were then analyzed to find the manufacturing cost of the parts using DFM. Then the cost analysis for the final assembly of the cart is carried out using DFA. An alternative design is suggested and re-estimation is carried out using the DFMA software. The re-designed shopping cart is shown in Fig. 2.

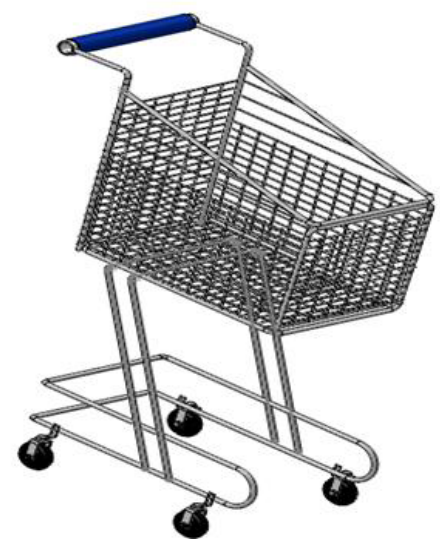

Figure 2. Re-designed shopping cart model.

Table 1. Part list and CAD model.

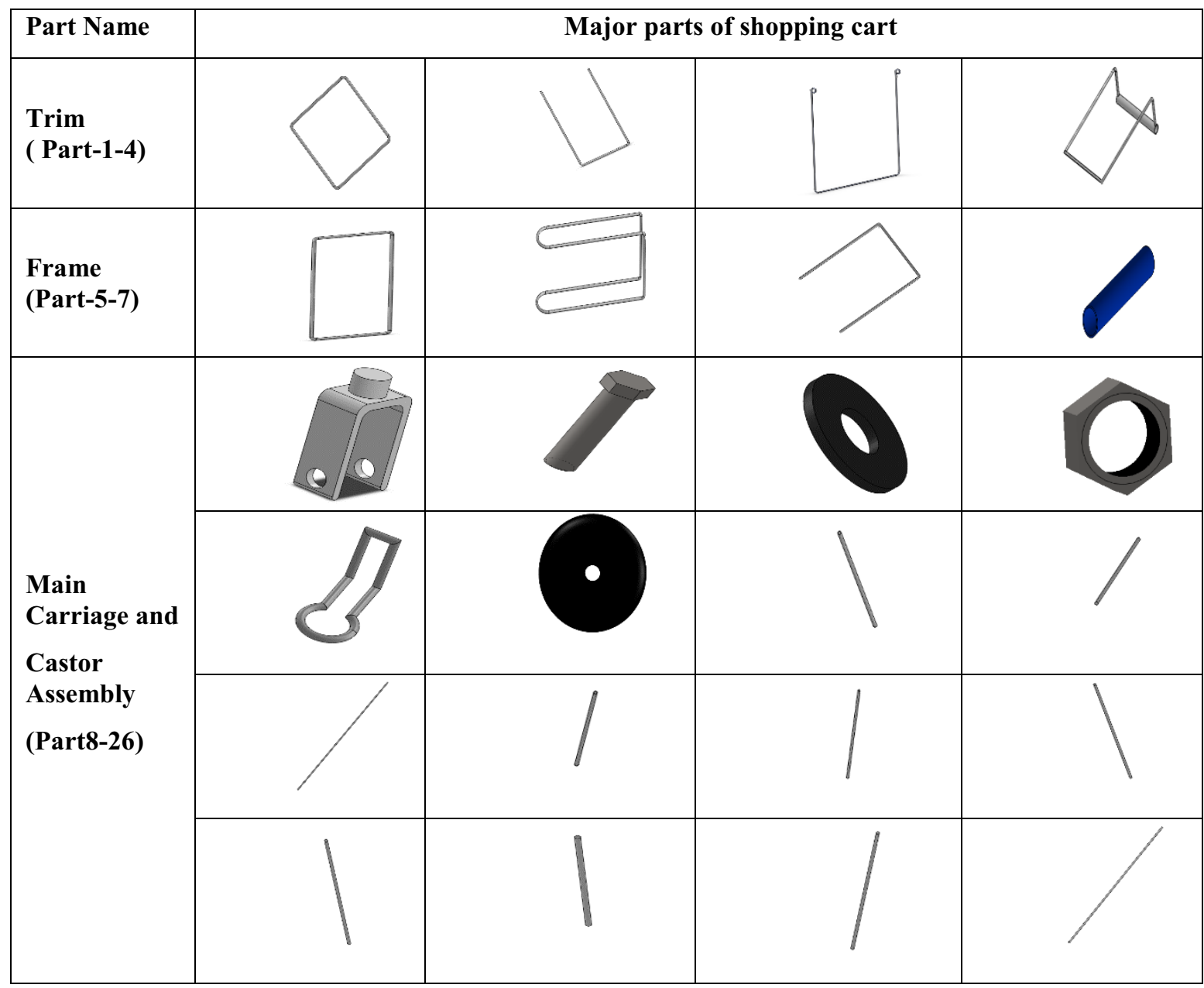




\section{DFM, DFA and concurrent costing of shopping cart assembly}

To estimate the costing analysis of the shopping cart, each part was first modeled usingSolidworks: CAD software and then the individual cost per part is found out, which includes the DFM procedure in the DFMA methodology. The analysis is done for a product life volume of 10,000 . DFM cost analysis of the final assembly with details of the individual partsincluded in the shopping cart is given in the table 2 and DFA cost analysis of the final assembly is given in the Table 3 .

\section{Redesign and analysis of shopping cart}

DFMA analysis was carried out for the alternative design of shopping cart with changes in a few parts. The redesigned cart had the same number count as that of the existing design. The analysis showed that there was no much change in cost while selecting the existing manufacturing process. Again analysis was carried out with an alternative design, which helped to reduce the cost from \$ 327 to \$ 314 . The DFMA analysis of redesigned cart for time saving and percentage reduction in assembly time is shown in Table 4.

Table 2. DFM cost analysis of the final assembly.

\begin{tabular}{|l|c|c|c|}
\hline \multicolumn{1}{|c|}{ Part Designation } & Total Count & Material & Total Item Cost(\$) \\
\hline Part 1-4 & 1 & Ferritic Stainless Steel & 50.04 \\
\hline Part 5-7 & 1 & Ferritic Stainless Steel & 46.45 \\
\hline Part 8-13 & 16 & Ferritic Stainless Steel & 81.30 \\
\hline Part 14-26 & 55 & Ferritic Stainless Steel & 116.76 \\
\hline \multicolumn{3}{|c|}{ Total } & 294.55 \\
\hline
\end{tabular}

Table 3. DFA of final assembly.

\begin{tabular}{|l|c|c|c|}
\hline \multicolumn{1}{|c|}{ Per Product data } & $\begin{array}{c}\text { Entities } \\
\text { (Including repeats) }\end{array}$ & $\begin{array}{c}\text { Labour } \\
\text { Time (s) }\end{array}$ & $\begin{array}{c}\text { Labour } \\
\text { Cost (\$) }\end{array}$ \\
\hline Component Parts & 240 & 3208.29 & 31.45 \\
\hline Subassemblies Partially or Fully Analyzed & 5 & 99.11 & 0.97 \\
\hline Subassemblies not to be Analyzed (excluded) & 0 & 0.00 & 0.00 \\
\hline Standard and Library Operations & 0 & 0.00 & 0.00 \\
\hline Totals & 245 & 3307.40 & 32.43 \\
\hline
\end{tabular}

Table 4. DFMA analysis of redesigned product.

\begin{tabular}{|c|c|c|c|c|c|c|c|}
\hline Part & Quantity & $\begin{array}{c}\text { Time } \\
\text { Savings( s) }\end{array}$ & $\begin{array}{c}\text { Percentage } \\
\text { Reduction (\%) }\end{array}$ & Part & Quantity & $\begin{array}{c}\text { Time } \\
\text { Savings (s) }\end{array}$ & $\begin{array}{c}\text { Percentage } \\
\text { Reduction (\%) }\end{array}$ \\
\hline Part 1 & 1 & 22.01 & 0.67 & Part 15 & 11 & 218.50 & 6.61 \\
\hline Part 2 & 1 & 4.01 & 0.12 & Part 16 & 15 & 296.90 & 8.98 \\
\hline Part 4 & 1 & 22.01 & 0.67 & Part 17 & 2 & 42.10 & 1.27 \\
\hline Part 5 & 1 & 22.01 & 0.67 & Part 18 & 7 & 140.10 & 4.24 \\
\hline Part 7 & 1 & 19.11 & 0.58 & Part 19 & 7 & 140.10 & 4.24 \\
\hline Part 8 & 16 & 120.16 & 3.63 & Part 20 & 7 & 132.75 & 4.01 \\
\hline Part 9 & 15 & 51.75 & 1.56 & Part 21 & 2 & 42.10 & 1.27 \\
\hline Part 10 & 16 & 106.80 & 3.23 & Part 22 & 2 & 40.00 & 1.21 \\
\hline Part 11 & 32 & 128.32 & 3.88 & Part 23 & 2 & 42.10 & 1.27 \\
\hline Part 12 & 16 & 36.04 & 1.09 & Part 24 & 11 & 218.50 & 6.61 \\
\hline Part 13 & 4 & 30.04 & 0.91 & Part 25 & 11 & 218.50 & 6.61 \\
\hline Part 14 & 55 & 1080.90 & 32.68 & Part 26 & 1 & 4.01 & 0.12 \\
\hline Total & Total Time Savings(s) & $\mathbf{3 1 7 8 . 8 2}$ & Total Percentage Reduction (\%) & $\mathbf{3 . 8 9}$ \\
\hline
\end{tabular}

\section{Conclusion}

The principle of DFMA is at least more than ten decades old, by which they provide a huge potential savings in design and manufacture of a product. Total time savings was found to be $3178.82 \mathrm{~s}$ and the percentage reduction in assembly time was reduced by $3.89 \%$. By using the DFMA software working in accordance with the Boothroyd principles, it is observed that the price of the existing product using the specified manufacturing process is $\$ 327$.
The alternative design to the existing product which is manufactured using commercially available weaved meshes of required gauge instead of casting the product itself has given a reduced price of $\$ 314$. This reduction in cost from $\$ 327$ to $\$ 314$ is due to the re-design of some parts which the resulted in ease of assembly and also elimination of welding at each and every joint which has led to great reduction in the manufacturing and assembly times. This shows that the modified product is better optimized than the existing original product. 


\section{Acknowledgement}

The authors wish to acknowledge the School of Mechanical Engineering (SMEC) and Product Design Laboratory, VIT University for supporting the project and for carrying out the study.

\section{References}

1. K. Asar, J. A. Day: A Knowledge Based Design Methodology for Manufacturing Assembly Lines, Computers and Industrial Engineering 41, no. 4, 441467 (2002)

2. M. Oakley, Product Design and Development in Small Firms, Operations Management Group, University of Aston Management Centre, vol. 3, no. 1, 5-10 (1982)
3. P. Dewhurst, G. Boothroyd, Early Cost Estimation in Product Design, Journal of Manufacturing Systems 26, no. 7, 505-520(1994)

4. F. H. Ramy, N. Sahmrani, DFMA, A Quantitative DFMA Methodology, Computer Aided Design and Application 7, no. 5, 701-709 (2010)

5. K. Elvin, H. Paul, K. Prabhu, Material consideration and Product Design: A Survey on Crucial Material Aspects used by Product Designers, Materials and Design 28, no. 6, 1081-1089 (2008)

6. K. Rong, H. Cheng-Long, A Framework for Automatic DFA System Development, Computers and Industrial Engineering 22, no. 4, 403-413(1992)

7. K. Annamalai, C. D. Naiju, S. Karthik, M. Mohan Prashanth: Early Cost Estimate of Product During Design Stage Using Design for Manufacturing and Assembly (DFMA) Principles, Advanced Material Research 622-623, 540-544(2013) 